\title{
Procesos gubernamentales que contribuyen a la gestión de residuos sólidos: una necesidad en la provincia de San Martín 2020
}

\author{
Lindsay Montilla Pérez \\ lmontilla@ucv.edu.pe
}

Dr. Keller Sánchez Dávila
ksanchezd@ ucv.edu.pe
Universidad César Vallejo

\section{RESUMEN}

La presente investigación fue planteada con el objetivo de conocer los procesos gubernamentales que favorecen la gestión de los residuos sólidos como parte de una necesidad en la provincia de San Martín, buscando identificar cuáles son los principales procesos intervinientes dentro de la gestión municipal, que hace posible el funcionamiento operativo integral de la gestión de residuos sólidos, utilizando de manera efectiva los recursos del estado en la parte económica, logística y de recursos humanos, para brindar una atención adecuada a la ciudadanía, enfocados en una economía circular; es de carácter descriptiva simple, con levantamiento de datos de revistas con información relevante en los resultados, la selección de las revistas están enfocadas en rescatar realidades de países Americanos (Norte, centro y sur). Entre los resultados se puede mencionar que las nuevas formas de gobernanza con enfoques integrales y nuevas visiones económicas con el enfoque circular, son determinantes para brindar la funcionalidad en los diversos procesos administrativos engranados con la eficiencia del sistema de los gobiernos locales en todas sus áreas, así también la parte operacional y participación activa de la ciudadanía como actores principales en los procesos de la gestión pública municipal, brinda una visión integral para mejorar las condiciones de todos los servicios, pues los investigadores precisan que mejorar las condiciones institucionales, principalmente en su la estructura y funcionalidad, puede generar cambios fundamentales para la reestructuración organizacional, que facilitara el acercamiento entre el gobierno y la ciudadanía.

Palabras clave: procesos gubernamentales; gobernanza; gestión integral; gestión de residuos sólidos, economía circular. 


\title{
Government processes that contribute to solid waste management: A necessity in the province of San Martín 2020
}

\begin{abstract}
This research was proposed with the objective of knowing the governmental processes that favor the management of solid waste as part of a need in the province of San Martín, seeking to identify which are the main intervening processes within municipal management, which makes it possible the integral operational operation of solid waste management, effectively using state resources in the economic, logistical and human resources part, to provide adequate attention to citizens, focused on a circular economy; It is of a simple descriptive nature, with data collection from journals with relevant information on the results, the selection of journals is focused on rescuing the realities of American countries (North, Center and South). Among the results, it can be mentioned that the new forms of governance with comprehensive approaches and new economic visions with the circular approach are decisive for providing functionality in the various administrative processes geared to the efficiency of the local government system in all its areas. as well as the operational part and active participation of citizens as main actors in the processes of municipal public management, provides a comprehensive vision to improve the conditions of all services, since researchers need to improve institutional conditions, mainly in their structure and functionality, can generate fundamental changes for organizational restructuring, which will facilitate the rapprochement between the government and the citizenry.
\end{abstract}

Keywords: government processes; governance; integral management; solid waste management, circular economy.

Artículo recibido: 18. Julio. 2021 Aceptado para publicación: 08. Agosto. 2021

Correspondencia: 1montilla@ucv.edu.pe Conflictos de Interés: Ninguna que declarar 


\section{INTRODUCCIÓN}

Con la finalidad de conocer los nuevos elementos que rigieron en el gobierno Chiloé en los años 2007 y 2009, se propusieron muchos postulados, entre los que sobresale la hipótesis donde sostiene que el centralismo político es impulsado por los diferentes pensamientos de trasformación permanente, entre lo que llamamos gobernanza y el enfoque de gestión territorial, pues el estado emplea la misma metodología que el gobierno central, quienes en su diseño de funcionamiento institucional no presentan alteración, puesto que estas alternativas estratégicas ayudan a legitimar las acciones del gobierno actual para los procesos de descentralización que enfocan los resultados en el empoderamiento de los territorios locales (Montecinos , Neira, Díaz, \& Park , 2019), Pues Cuba presenta un nuevo concepto de gestión enfocado en la coyuntura de identificación de nuevas estrategias para gestionar de manera adecuada los recursos patrimoniales en el ámbito local para el desarrollo municipal, generando instrumentos de carácter decisivo donde los problemas que abraca un sistema de desarrollo pueden ser tratados de tal manera que se instalen en un enfoque multidimensional, con la misión de disminuir impactos que sean desfavorables para la gestión, entre estas estrategias se puede mencionar la creación y cooperación de proponer nuevas políticas públicas, con visión de compromisos y responsabilidades compartidos entre los actores locales y los miembros de la sociedad.

En consecuencia a lo antes mencionado, la formulación e implementación de estas estrategias, permitirá la complementariedad entre los procesos locales para el desarrollo sostenible entre los territorios bajo el enfoque de gestión integrada, en la que se sostiene una propuesta de valor a los recursos y bienes sociales internos que promueven acciones de beneficio en el tiempo actual, con proyecciones de mejora en el futuro, basados en la realidad presente (PremierI, 2020).

En referencia al país mexicano se puede incidir que los órganos municipales en su artículo constitucional político de los Estados Unidos Mexicano $\mathrm{N}^{\circ} 115$, menciona que para garantizar la calidad de vida de los ciudadanos los servicios públicos y el control demográfico por efecto de las migraciones poblacionales de zonas rurales a urbanas están bajo la responsabilidad del estado; lo que genera la necesidad de una mejor planificación en cuanto a infraestructura y utilización de los recursos para generar mejoras en el sistema organización y operativo. 
La utilización de la tecnología en las áreas de gestión y operacionalización de las entidades públicas, conlleva a los tomadores de decisiones a mejorar los procesos administrativos y funcionales de las áreas descentralizadas, identificando instrumentos, programas, recursos materiales con dotación tecnológica que aportan a la ejecución de acciones fundamentales en la cadena operativa del sistema municipal para cumplir con las metas y objetivos planteados, en los que las empresas, ciudadanía y actores municipales deberían participar de manera integrada enfocada a brindar una solución a las problemáticas sociales encontradas en la comunidad con una adecuada gestión tecnológica municipal (Rubio-Núñez, Valencia, Peña-Cheng, \& Rodríguez-Muñoz, 2018).

El continuo crecimiento de las industrias con la acelerada producción de insumos para satisfacer necesidades humanas con el consumismo y el constante crecimiento de las ciudades y junto con ella satisfacer sus necesidades, han generado una gran afectación al medio ambiente, debiendo analizar y tomar decisiones prontas que permitas establecer espacios geográficos adecuados para llevar a cabo el correcto manejo de los residuos sólidos, acompañado de un buen plan de gestión desde la generación hasta la disposición final, realzando que la recolección de los mismos es un punto importante para optimizar los recursos logísticos, de maquinaria, horas hombre, rutas adecuadas que permitirán efectivizar las acciones de gestión municipal, puesto que al prescindir de una correcta programación estos desechos comienzan a invadir y contaminar de manera progresiva a la población que se encuentran en la periferie de la ciudad, ocasionando que la población se vuelva vulnerable ante la presencia de agentes transmisores de alguna enfermedad, así como la contaminación ambiental por olores, visuales, tóxicos, con afectación al suelo y en algunos casos al agua que es un recursos esencial para todos los seres vivos, esta repercusión va directamente a la parte economía, el ecosistema, el turismo, el desarrollo y el progreso de la región como lo mencionan Kumar, Sunita, Saravanan, \& Yaashikaa (2019) citado por (Monroy Gutiérrez, Díaz Ochoa, Vera Guarnizo, \& Monroy Gutiérrez, 2021).

Los ayuntamientos españoles han creado conciencia sobre la afectación que tiene la generación y mala disposición de los residuos sólidos en el medio ambiente, por ello vienen trabajando con una correcta gestión en cuanto al recojo y tratamiento de los mismos, la economía circular pretende ser un modelo de interés común entre la 
participación de las administraciones publicas y los ciudadanos, en consecuencia la desconfianza que ha generado las diversas acciones de corrupción en estas instituciones públicas, ha conllevado a generar nuevas políticas publicas basadas en la transparencia de la gestión instaurando herramientas que devuelvan la legitimidad a las AAPP, para consolidar la correcta gobernabilidad y mejora en los procesos de gobierno. Por ello se presenta una propuesta que consiste en evaluar los niveles de transparencia municipal en relación a la gestión de los RSU, considerando de un cuadro de 64 indicadores, distribuidos en 7 áreas de evaluación con idiosincrasias diferentes entre lo legal, la parte presupuestaria, infraestructuras, calidad de la información de la gestión y actividades de recojo y tratamientos de los residuos municipales, difundidas en los portales web y de transparencia en los 96 ayuntamientos españoles analizados. (Rodríguez \& Palomo Zurdo, 2020)

Tener una sobreproducción de residuos sólidos urbanos (RSU) con mala disposición final, genera una afectación directa al medio ambiente, y a la salud humana, tal es el caso de la parroquia de Limoncocha la cual se ubica en la Amazonía ecuatoriana, el cual dispone sus desechos sólidos en un botadero al aire libre sin tomar medida alguna, por ellos se plantó un estudio que se enfoca en analizar las propiedades, físicas y biológicas de los residuos sólidos urbanos con la finalidad de obtener un aprovechamiento justo de las materias orgánicas e inorgánicas como generadoras de energía utilizando como técnica la incineración aprovechando el poder calórico obteniendo como resultados que el $92 \%$ en peso contienen potencial energético superior a $3100 \mathrm{kcal} / \mathrm{kg}$, pudiendo ser sometidos a procesos de aprovechamiento energético (Coral Carrillo, Oviedo Costales , \& Rodríguez Machado, 2021).

El vertido de residuos orgánicos sigue siendo el método de gestión de residuos predominante en Canadá, la recopilación de datos y el análisis de los desechos realizados para el estudio de caso de la ciudad de Montreal, llevó a cabo una evaluación del ciclo de vida del sistema de gestión de residuos actuales utilizando el software IWM-2. En los resultados de la evaluación del ciclo de vida, se utilizó un algoritmo genético de clasificación no dominado para optimizar los flujos de residuos, pues la optimización mostró que el índice de recuperación de residuos orgánicos fue del 23\% en 2017, pues este podría aumentarse al $100 \%$ de recuperación de residuos alimentarios. Además, se 
podría duplicar el reciclaje y reducir a la mitad los vertederos. (Tahereh Malmir, Saeed Ranjbar, \& Ursula Eicker, 2020).

La gestión de residuos sólidos urbanos es uno de los principales problemas en todo el mundo. La gestión inadecuada de los residuos sólidos urbanos (RSU) puede representar un peligro importante. El procesamiento anaeróbico de RSU seguido de la generación de metano y biogás es una de las numerosas opciones de fuentes de energía sostenibles. En comparación con otras tecnologías aplicables para el tratamiento de RSU, factores como los aspectos económicos, el ahorro de energía y las ventajas ecológicas hacen que el procesamiento anaeróbico sea una opción atractiva. Esta revisión analiza el marco para evaluar la conversión de residuos sólidos urbanos en energía y la bioeconomía derivada de los residuos con el fin de abordar los objetivos de desarrollo sostenible. Además, esta revisión proporcionará una base de trabajo innovadora para mejorar la precisión de la estructuración, el control de calidad, y pretratamiento para el tratamiento ideal de diferentes segmentos de RSU para lograr una bioeconomía circular sostenible (Yaashikaa , Kumar Ponnusamy, Saravanan Anbalagan, Sunita J, \& Racchana Ramamurthy, 2020)

\section{ESTRATEGIAS METODOLÓGICAS O MATERIALES Y MÉTODOS}

\section{Diseño de estudio.}

El presente trabajo de revisión sistemática fue analizado por docentes especialistas en investigación de la Escuela de Posgrado de la universidad César Vallejo, sede Tarapoto, San Martín, cuya obtención de datos fue realizada en un periodo de 15 días (del 01 al 16 de Julio del 2021).

\section{Criterios de elegibilidad}

Tipos de participantes: Se consideraron estudios que incluían la participación de adultos y personas mayores servidores en los gobiernos locales, y se excluyeron fuentes bibliográficas de naturaleza teórica. Tipos de estudios: Considerando el número limitado de estudios sobre procesos gubernamentales en los gobiernos locales en Latinoamérica, se proyecta como objetivo diseñar un mapa de conocimientos y estudios existentes sobre el tema e identificar los diseños de estudio por el nivel de las pruebas. Tipos de resultados: Los resultados de las investigaciones en nivel primario fueron seleccionados con los siguientes criterios: casos de estudios, investigaciones empíricas, experiencias y otros similares.

\section{Búsqueda de estudios}


Se ejecutó la exploración manual utilizando las referencias de los estudios principales y secundarios encontrados en la Web. Estas indagaciones se realizaron de manera ordenada y directa en la base de datos de SCOPUS, Scielo, researchgate, risti, dialnet, ciencialatina referente a los últimos 3 años.

\section{Selección de estudios}

La selección de los estudios fue realizada mediante un proceso en los que intervinieron dos revisores independientes, y cualquier divergencia fue resuelta por un tercer revisor. Los estudios fueron seleccionados en dos etapas. La primera radicó en revisar los títulos y resúmenes de las referencias encontradas en los portales web de renombre seleccionando los estudios potencialmente elegibles. El segundo paso consistió en revisar y analiza el contenido de los textos que fueron preseleccionados en su y confirmar que son estudios con relevancia científica que contextualizan el objeto de estudio. 


\section{RESULTADOS Y DISCUSIÓN}

\subsection{Tablas 1: Estudios revisados sobre Procesos Gubernamentales.}

DATOS DE LA PUBLICACION

\begin{tabular}{|c|c|c|c|c|}
\hline 1. Autor & Año & Nombre de la Investigación & $\begin{array}{c}\text { Revista donde su ubica la } \\
\text { publicación }\end{array}$ & Volumen y número \\
\hline $\begin{array}{l}\text { Ana Verónica } \\
\text { Polack, Sergio } \\
\text { Martínez Silva, } \\
\text { Cesar } \\
\text { Alejandro } \\
\text { Ramírez } \\
\text { Chaparro. }\end{array}$ & $(2019)$ & $\begin{array}{c}\text { Las asociaciones público-privadas como instrumento de } \\
\text { gobernanza colaborativa: apuntes para el debate y retos para la } \\
\text { gestión. }\end{array}$ & $\begin{array}{l}\text { https://revistas.unab.edu.co/inde } \\
\text { x.php/reflexion/article/view/373 } \\
0\end{array}$ & $\begin{array}{l}\text { Vol. 21, núm. } 43 \text {, setiembre } \\
\text { 2019; } \\
\text { pág. } 171-183\end{array}$ \\
\hline
\end{tabular}

\section{CONTENIDO DE LA PUBLICACION}

\begin{tabular}{|c|c|c|c|c|c|}
\hline $\begin{array}{l}\text { Tipo y Diseño de } \\
\text { Investigación }\end{array}$ & $\begin{array}{c}\text { Población y } \\
\text { Muestra }\end{array}$ & Instrumentos & Aspectos éticos & Resultados & Conclusión \\
\hline $\begin{array}{l}\text { No experimental } \\
\text { documental }\end{array}$ & $\begin{array}{l}23 \text { artículos } \\
\text { científicos }\end{array}$ & $\begin{array}{l}\text { Revisión } \\
\text { documentaria }\end{array}$ & $\begin{array}{l}\text { No conflicto de } \\
\text { interés }\end{array}$ & $\begin{array}{l}\text { Propone sugerir modelos de } \\
\text { explicación y compromiso } \\
\text { adecuada para nuevas habilidades } \\
\text { de gobierno, direccionado a } \\
\text { determinar y urbanizar } \\
\text { capacidades institucionales a nivel } \\
\text { doméstico y subnacional para la } \\
\text { negociación de las acciones de } \\
\text { protección-privada y entender los } \\
\text { desafíos democráticos que implica } \\
\text { su aprovechamiento. }\end{array}$ & $\begin{array}{l}\text { Las Asociaciones Publico Privads convienen ser } \\
\text { vistas como una herramienta de propósitos } \\
\text { públicos desde el punto de vista de creación, } \\
\text { desarrollo, y mejora de las operaciones y el } \\
\text { mantenimiento de la infraestructura pública bajo } \\
\text { los mecanismos contractuales permitidos y no } \\
\text { como opción de negocio en lo privado. }\end{array}$ \\
\hline
\end{tabular}


DATOS DE LA PUBLICACION

\begin{tabular}{|c|c|c|c|c|}
\hline 2. Autor & Año & Nombre de la Investigación & $\begin{array}{c}\text { Revista donde su ubica la } \\
\text { publicación }\end{array}$ & Volumen y número \\
\hline $\begin{array}{c}\text { Franci } \\
\text { sco Lo } \\
\text { ngo. }\end{array}$ & $(2020)$ & Gobernanza pública para la innovación. & $\begin{array}{c}\text { https://www.redalyc.org/articulo.oa } \\
\text { ?id=357565951002 }\end{array}$ & $\begin{array}{l}\text { núm. } 76 \text {, marzo 2020; } \\
\text { pág. } 1315-2378\end{array}$ \\
\hline
\end{tabular}

\begin{tabular}{|c|c|c|c|c|c|}
\hline \multicolumn{6}{|c|}{ CONTENIDO DE LA PUBLICACION } \\
\hline $\begin{array}{l}\text { Tipo y Diseño de } \\
\text { Investigación }\end{array}$ & Población y Muestra & Instrumentos & $\begin{array}{l}\text { Aspectos } \\
\text { éticos }\end{array}$ & Resultados & Conclusión \\
\hline $\begin{array}{l}\text { No experimental } \\
\text { documental }\end{array}$ & 12 artículos científicos & $\begin{array}{l}\text { Revisión } \\
\text { documentaria }\end{array}$ & $\begin{array}{l}\text { No conflicto } \\
\text { de interés }\end{array}$ & $\begin{array}{l}\text { El estudio dio a conocer principios } \\
\text { fundamentales bajo una nueva perspectiva } \\
\text { de gobernanza, que pueda proyectar a los } \\
\text { gobiernos y sus organizaciones a la } \\
\text { exploración, la experimentación, la apertura, } \\
\text { la colaboración y participación conjunta con } \\
\text { representantes externos situados fuera del } \\
\text { sistema público, con el propósito de } \\
\text { mantener la transparencia en la rendición de } \\
\text { cuentas de gestión local, las cuales debe } \\
\text { responder a las necesidades de la ciudadanía } \\
\text { y el bien social. }\end{array}$ & $\begin{array}{l}\text { Los retos en gestión } \\
\text { pública obligan a la parte } \\
\text { administrativa a asumir } \\
\text { una agenda de } \\
\text { innovación ambiciosa y } \\
\text { radical. El alcance de esa } \\
\text { agenda obliga al sector } \\
\text { público a reflexionar y } \\
\text { restructurar algunos de } \\
\text { los arreglos } \\
\text { institucionales básicos } \\
\text { que caracterizan al statu } \\
\text { quo actual. }\end{array}$ \\
\hline
\end{tabular}




\begin{tabular}{|c|c|c|c|c|}
\hline 3. Autor & Año & Nombre de la Investigación & $\begin{array}{c}\text { Revista donde su ubica la } \\
\text { publicación }\end{array}$ & Volumen y número \\
\hline $\begin{array}{c}\text { Juedir Viana } \\
\text { Teixeira, Artur } \\
\text { Angelo Ramos } \\
\text { Lamenha. }\end{array}$ & $(2018)$ & $\begin{array}{c}\text { índices De Transparencia Y Gestión En Las Entidades Públicas } \\
\text { Como Herramienta De Control Y Desempeño: Una Comparación } \\
\text { Entre Indicadores Municipales En Alagoas - Brasil. }\end{array}$ & $\begin{array}{c}\text { https://www.redalyc.org/articulo. } \\
\text { oa? id=357959548005 }\end{array}$ & $\begin{array}{l}\text { Vol. Octubre - 2018; } \\
\text { pág: } 75-95 .\end{array}$ \\
\hline
\end{tabular}

\section{CONTENIDO DE LA PUBLICACION}

\begin{tabular}{|c|c|c|c|c|c|}
\hline $\begin{array}{l}\text { Tipo y Diseño de } \\
\text { Investigación }\end{array}$ & Población y Muestra & Instrumentos & $\begin{array}{l}\text { Aspectos } \\
\text { éticos }\end{array}$ & Resultados & Conclusión \\
\hline $\begin{array}{l}\text { Descriptiva y } \\
\text { cuantitativa, } \\
\text { comparativa }\end{array}$ & 102 Municipios. & Matriz de análisis & $\begin{array}{l}\text { No conflicto } \\
\text { de interés }\end{array}$ & $\begin{array}{l}\text { La gran mayoría de los órganos municipales no } \\
\text { precisan la ejecución de nuevas estrategias } \\
\text { degobernanza digital dentro de su organización, } \\
\text { por ello es preciso acompañar y correlacionar } \\
\text { los diversos cuadros de control administrativa, } \\
\text { gestión de procesos y resultados de metas para } \\
\text { prever la posibilidad de implementarlas, así la } \\
\text { disponibilidad de la legislación, la socialización } \\
\text { de documentos públicos en el portal de } \\
\text { transparencia, información sobre los procesos } \\
\text { de licitación, concursos públicos, balances } \\
\text { económicos, guía telefónica de los gestores y } \\
\text { noticias son puntos importantes que el } \\
\text { municipio debe tener en cuenta, para dar a } \\
\text { conocer la transparencia de sus procesos y el } \\
\text { desempeño de sus funcionarios. }\end{array}$ & $\begin{array}{l}\text { Es importante conocer la } \\
\text { correlación entre los } \\
\text { diversos cuadros de } \\
\text { control, gestión y } \\
\text { resultados municipales } \\
\text { pues muchos GL, no se } \\
\text { acogen a las prácticas de } \\
\text { gobernanza digital, a } \\
\text { pesar de la posibilidad de } \\
\text { implementarlas como } \\
\text { apoyo a la gestión de } \\
\text { procesos, y demostrar } \\
\text { transparencia en cada } \\
\text { uno de ellos. }\end{array}$ \\
\hline
\end{tabular}

Ciencia Latina Revista Científica Multidisciplinar, Ciudad de México, México.

ISN 2707-2207 / ISSN 2707-2215 (en línea), julio-agosto, 2021, Volumen 5, Número 4. https://doi.org/10.37811/cl rcm.v5i4.765 p.6158 
DATOS DE LA PUBLICACION

\begin{tabular}{ccccc}
\hline 4. Autor & Año & Nombre de la Investigación & $\begin{array}{c}\text { Revista donde su ubica la } \\
\text { publicación }\end{array}$ & Volumen y número \\
\hline Aleida González & $(2019)$ & Herramientas para la gestión por procesos. & $\frac{\text { https://www.redalyc.org/articulo. }}{\text { oa? id=409659500003 }}$ & Vol.15, N ${ }^{\circ} 28$, Mayo $-2019 ;$ \\
González, & & & \\
Lisandra Leal & & & \\
Rodríguez, & & & \\
Daymí Martínez & & & \\
Caballero & & & \\
\hline
\end{tabular}

\section{CONTENIDO DE LA PUBLICACION}

\begin{tabular}{|c|c|c|c|c|c|}
\hline \multicolumn{6}{|c|}{ CONTENIDO DE LA PUBLICACION } \\
\hline $\begin{array}{c}\text { Tipo y Diseño } \\
\text { de } \\
\text { Investigación }\end{array}$ & Población y Muestra & Instrumentos & $\begin{array}{l}\text { Aspectos } \\
\text { éticos }\end{array}$ & Resultados & Conclusión \\
\hline $\begin{array}{l}\text { No } \\
\text { experimental - } \\
\text { documental }\end{array}$ & 52 artículos científicos & $\begin{array}{l}\text { Revisión } \\
\text { documentaria }\end{array}$ & $\begin{array}{l}\text { No conflicto } \\
\text { de interés }\end{array}$ & $\begin{array}{l}\text { El reto de las organizaciones tiene origen y se acentúa } \\
\text { en la acción dinámica que se establece para la } \\
\text { identificación de las exigencias del entorno social, así } \\
\text { las organizaciones ejecutan cambios en los sistemas } \\
\text { administrativos de manera eficaz teniendo en cuenta } \\
\text { los plazos que aseguren una ventaja ante las acciones } \\
\text { programadas, esto para mantener la eficacia y } \\
\text { eficiencia de las tareas programadas basada en los } \\
\text { procesos que se orientan a conseguir los resultados. }\end{array}$ & $\begin{array}{l}\text { Las nuevas concepciones } \\
\text { adquiridas por las empresas, } \\
\text { son diseñadas a partir de las } \\
\text { TIC, afianzadas a los } \\
\text { objetivos organizacionales, } \\
\text { con la cual los procesos de } \\
\text { gestión y estructura del } \\
\text { sistema de tecnologías de la } \\
\text { información, se verán } \\
\text { reflejadas en la integración y } \\
\text { la estandarización de } \\
\text { requerimientos de la } \\
\text { organización. }\end{array}$ \\
\hline
\end{tabular}

Ciencia Latina Revista Científica Multidisciplinar, Ciudad de México, México.

ISN 2707-2207 / ISSN 2707-2215 (en línea), julio-agosto, 2021, Volumen 5, Número 4. https://doi.org/10.37811/cl rcm.v5i4.765 p.6159 


\section{DATOS DE LA PUBLICACION}

\begin{tabular}{|c|c|c|c|c|}
\hline 5. Autor & Año & Nombre de la Investigación & $\begin{array}{c}\text { Revista donde su ubica la } \\
\text { publicación }\end{array}$ & Volumen y número \\
\hline $\begin{array}{l}\text { Yudith Salvador } \\
\text {-Hernández, } \\
\text { Mariluz Llanes- } \\
\text { Font, Reynaldo } \\
\text { Velázquez- } \\
\text { Zaldívar. }\end{array}$ & (2018) & $\begin{array}{l}\text { Gestión por procesos en la participación ciudadana. } \\
\text { Aplicación en el territorio Holguinero }\end{array}$ & $\begin{array}{l}\text { https://www.redalyc.org/articulo.oa?i } \\
\qquad \mathrm{d}=360458834007\end{array}$ & $\begin{array}{l}\text { vol. 40, septiembre } 2018 \text {, pág. } 59- \\
66\end{array}$ \\
\hline
\end{tabular}

\begin{tabular}{|c|c|c|c|c|c|}
\hline \multicolumn{6}{|c|}{ CONTENIDO DE LA PUBLICACION } \\
\hline $\begin{array}{c}\text { Tipo y Diseño } \\
\text { de } \\
\text { Investigación }\end{array}$ & $\begin{array}{c}\text { Población y } \\
\text { Muestra }\end{array}$ & Instrumentos & $\begin{array}{l}\text { Aspectos } \\
\text { éticos }\end{array}$ & Resultados & Conclusión \\
\hline $\begin{array}{c}\text { No } \\
\text { experimental - } \\
\text { documental }\end{array}$ & $\begin{array}{c}\text { +100 artículos } \\
\text { científicos }\end{array}$ & $\begin{array}{l}\text { Revisión } \\
\text { documentaria }\end{array}$ & $\begin{array}{l}\text { No conflicto } \\
\text { de interés }\end{array}$ & $\begin{array}{l}\text { Las entidades privadas presentan buenas prácticas } \\
\text { organizacionales de gestión las cuales trascendieron } \\
\text { en el mejoramiento de los procesos la administrativos } \\
\text { en la acción pública teniendo como ejemplo los casos } \\
\text { de México, Colombia y España los cuales adoptaron } \\
\text { nuevas metodologías de gestión entre ellas implantar } \\
\text { herramientas de calidad enfocado a evaluar los } \\
\text { procesos de los sectores de salud, educación y } \\
\text { gobiernos locales con el propósito de lograr la } \\
\text { efectividad en sus atenciones en post de satisfacer las } \\
\text { necesidades de la población como eje fundamental } \\
\text { del servicio público. }\end{array}$ & $\begin{array}{l}\text { La participación de la ciudadanía } \\
\text { es un punto clave en la } \\
\text { implementación de políticas } \\
\text { públicas, puesto que dá a conocer } \\
\text { las necesidades que aqueja la } \\
\text { misma de manera real y objetiva } \\
\text { fortaleciendo y generando lazos y } \\
\text { alianzas para generar mayores } \\
\text { esfuerzos de gestión socialista } \\
\text { teniendo en cuenta las } \\
\text { potencialidades del territorio y la } \\
\text { comunidad. }\end{array}$ \\
\hline
\end{tabular}

Ciencia Latina Revista Científica Multidisciplinar, Ciudad de México, México.

ISN 2707-2207 / ISSN 2707-2215 (en línea), julio-agosto, 2021, Volumen 5, Número 4. https://doi.org/10.37811/cl rcm.v5i4.765 p.6160 


\section{DATOS DE LA PUBLICACION}

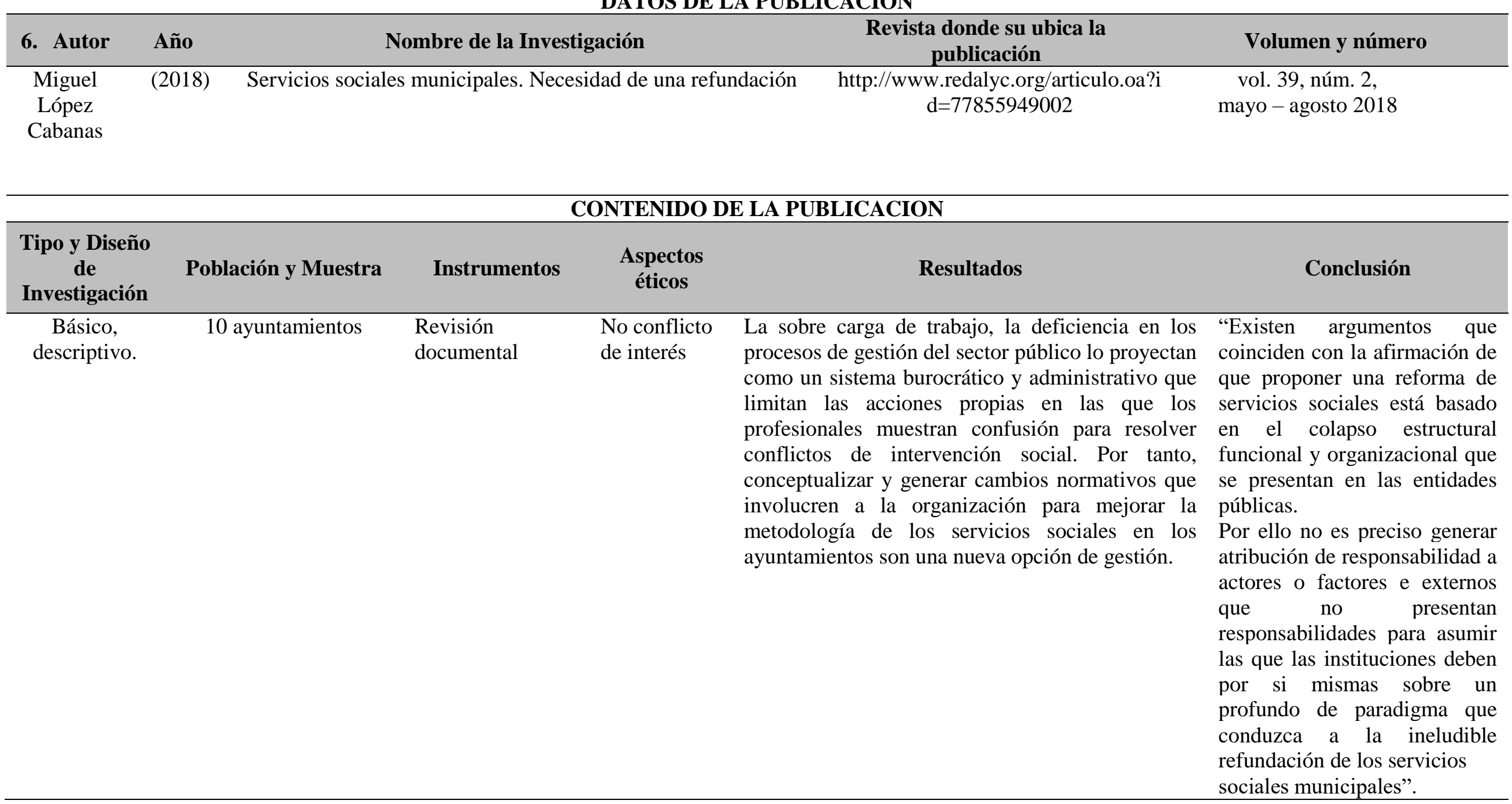

Ciencia Latina Revista Científica Multidisciplinar, Ciudad de México, México. 


\section{DATOS DE LA PUBLICACION}

\begin{tabular}{|c|c|c|c|c|}
\hline Autor & Año & Nombre de la Investigación & $\begin{array}{l}\text { Revista donde su ubica la } \\
\text { publicación }\end{array}$ & Volumen y número \\
\hline $\begin{array}{l}\text { Mariela Cuadr } \\
\text { o }\end{array}$ & $(2020)$ & $\begin{array}{c}\text { Lo internacional y lo global. Gubernamentalidad global: } \\
\text { analítica y práctica de gobierno. }\end{array}$ & $\begin{array}{c}\text { https://www.redalyc.org/articulo.oa? } \\
\text { id }=81263024002\end{array}$ & $\begin{array}{l}\text { núm. 102, Sep -2019 pág. 23- } \\
39\end{array}$ \\
\hline
\end{tabular}

\section{CONTENIDO DE LA PUBLICACION}

\begin{tabular}{|c|c|c|c|c|c|}
\hline $\begin{array}{c}\text { Tipo y Diseño } \\
\text { de } \\
\text { Investigación }\end{array}$ & Población y Muestra & Instrumentos & $\begin{array}{l}\text { Aspectos } \\
\text { éticos }\end{array}$ & Resultados & Conclusión \\
\hline $\begin{array}{c}\text { No } \\
\text { experimental - } \\
\text { documental }\end{array}$ & 31 artículos & $\begin{array}{l}\text { Revisión } \\
\text { documental }\end{array}$ & $\begin{array}{l}\text { No conflicto } \\
\text { de interés }\end{array}$ & $\begin{array}{l}\text { Se argumentó que el valor de la } \\
\text { gubernamentalidad radica en permitir evitar el } \\
\text { nacionalismo metodológico, enfocado al } \\
\text { estudio de la tendencia de discursos, } \\
\text { instituciones, problematizaciones, procesos y } \\
\text { redes constitutivas de una política que en el } \\
\text { tiempo son internacionales y globales. La } \\
\text { gubernamentalidad pone la atención también en } \\
\text { nuestros deseos como sujetos de gobierno, nos } \\
\text { compele a reflexionar sobre nuestro rol en el } \\
\text { ejercicio del poder global cuanto deseamos para } \\
\text { nosotros y para los otros. También permite } \\
\text { explorar desde otro punto de vista las múltiples } \\
\text { prácticas intervencionistas que constituyen al } \\
\text { gobierno global y repensar nociones como las } \\
\text { de gobernanza. }\end{array}$ & 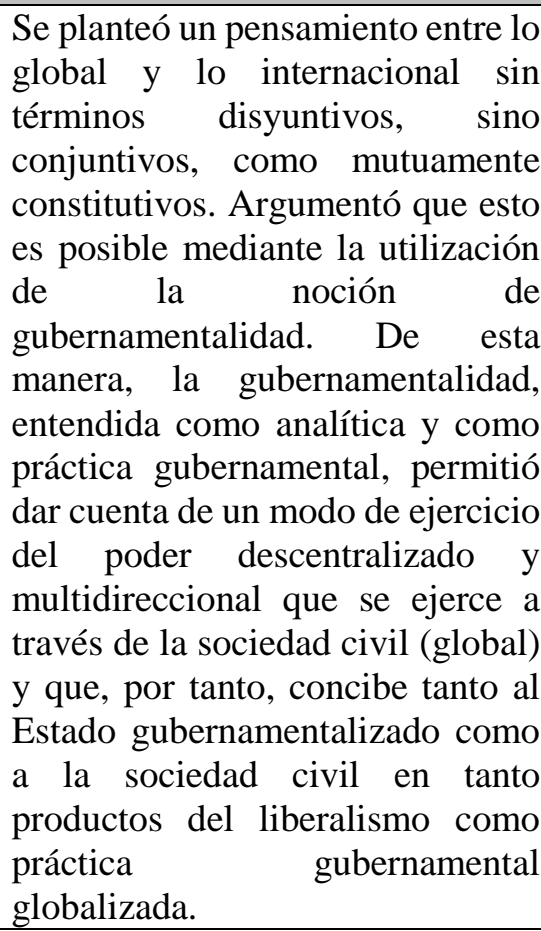 \\
\hline
\end{tabular}




\section{DATOS DE LA PUBLICACION}

\begin{tabular}{|c|c|c|c|c|}
\hline Autor & Año & Nombre de la Investigación & $\begin{array}{c}\text { Revista donde su ubica la } \\
\text { publicación }\end{array}$ & Volumen y número \\
\hline $\begin{array}{l}\text { Daniel Javier De la } \\
\text { Garza } \\
\text { Montemayor, Elisa } \\
\text { R Yllán Ramírez, } \\
\text { Daniel Barredo } \\
\text { Ibáñez }\end{array}$ & $(2018)$ & $\begin{array}{c}\text { Tendencias en la administración pública moderna: la } \\
\text { nueva gestión pública en México }\end{array}$ & $\begin{array}{l}\text { https://www.redalyc.org/articulo.oa?i } \\
\text { d=29055767003 }\end{array}$ & $\begin{array}{c}\text { Vol: } 23, \mathrm{~N}^{\circ} 81 \text {, enero } 2018 \text {; } \\
\text { pág. } 31-48\end{array}$ \\
\hline
\end{tabular}

\section{CONTENIDO DE LA PUBLICACION}

\begin{tabular}{|c|c|c|c|c|c|}
\hline $\begin{array}{l}\text { Tipo y Diseño de } \\
\text { Investigación }\end{array}$ & Población y Muestra & Instrumentos & $\begin{array}{l}\text { Aspectos } \\
\text { éticos }\end{array}$ & Resultados & Conclusión \\
\hline $\begin{array}{l}\text { No experimental - } \\
\text { documental. }\end{array}$ & 27 artículos & $\begin{array}{l}\text { Revisión } \\
\text { documental }\end{array}$ & $\begin{array}{l}\text { No conflicto } \\
\text { de interés }\end{array}$ & $\begin{array}{l}\text { Es estudio menciona que excluir la } \\
\text { participación de los ciudadanos por edad, así } \\
\text { como la integrar a los miembros de las } \\
\text { empresas mas importantes, no tiene } \\
\text { aplicación en determinadas sociedades como } \\
\text { es el caso de la comunidad mexicana, que no } \\
\text { parte de las generalizaciones de las } \\
\text { preposiciones de la nueva gestión pública. }\end{array}$ & $\begin{array}{l}\text { Se argumenta que al no existir } \\
\text { una articulación entre la } \\
\text { administración pública y la } \\
\text { legitimidad puesto que no se } \\
\text { consideran las demandas } \\
\text { ciudadanas en el manejo de los } \\
\text { recursos públicos que generan } \\
\text { un desfasamiento, de la } \\
\text { eficiencia en los procesos de } \\
\text { gestión municipal. }\end{array}$ \\
\hline
\end{tabular}

Ciencia Latina Revista Científica Multidisciplinar, Ciudad de México, México. ISN 2707-2207 / ISSN 2707-2215 (en línea), julio-agosto, 2021, Volumen 5, Número 4. https://doi.org/10.37811/cl rcm.v5i4.765 p.6163 


\section{DATOS DE LA PUBLICACION}

\begin{tabular}{|c|c|c|c|c|}
\hline Autor & Año & Nombre de la Investigación & $\begin{array}{c}\text { Revista donde su ubica la } \\
\text { publicación }\end{array}$ & Volumen y número \\
\hline $\begin{array}{l}\text { Herbert Cristhiano } \\
\text { Pinheiro de } \\
\text { Andrade, Ana } \\
\text { Maria de } \\
\text { Albuquerque } \\
\text { Vasconcellos, } \\
\text { Mário Vasconcellos } \\
\text { Sobrinho }\end{array}$ & (2018) & $\begin{array}{l}\text { Coproducción e Incidencia de la Sociedad Civil en la } \\
\text { Política de Residuos Sólidos en Belém, Amazonia }\end{array}$ & $\begin{array}{l}\text { https://www.redalyc.org/articulo.oa?i } \\
\qquad \mathrm{d}=351562414011\end{array}$ & $\begin{array}{l}\text { Vol: 12, núm. 02, enero } 2018 . \\
\text { pág. } 1-16\end{array}$ \\
\hline
\end{tabular}

Sobrinho

\section{CONTENIDO DE LA PUBLICACION}

\begin{tabular}{|c|c|c|c|c|}
\hline $\begin{array}{l}\text { Tipo y Diseño de } \\
\text { Investigación }\end{array}$ & Población y Muestra & Instrumentos & $\begin{array}{l}\text { Aspectos } \\
\text { éticos }\end{array}$ & Resultados \\
\hline $\begin{array}{c}\text { Básico, descriptivo. } \\
\text { Revisión } \\
\text { documentaria }\end{array}$ & $\begin{array}{l}1 \text { organización } 16 \\
\text { representantes }\end{array}$ & Cuestionario & $\begin{array}{l}\text { No conflicto } \\
\text { de interés }\end{array}$ & $\begin{array}{l}\text { Surgieron nuevas técnicas de planeación para } \\
\text { la presentación y rendición de cuentas del } \\
\text { gobierno, en el que se plasma el estudio de } \\
\text { cumplimiento de los criterios de eficiencia } \\
\text { aplicado a la gestión pública, constatando } \\
\text { que acciones de cooperación entre los } \\
\text { gestores públicos y la población generan } \\
\text { confianza entre actores directos e indirectos, } \\
\text { sobre el gobierno de turno. }\end{array}$ \\
\hline
\end{tabular}

\section{Conclusión}

La coproducción es una alternativa para la sociedad civil en la que se pueda incidir en el rumbo de la política pública para la mejorar los servicios públicos prestados en su territorio. En un contexto de conflictos socioambientales en el territorio, algunos actores interactúan en el espacio público para dialogar, deliberar y tomar decisiones sobre sus problemas. La capacidad política coproductiva de los actores se revela fundamental para movilizar, mediar, conectar, equilibrar y democratizar interacciones descentralizadoras. 
3.2. Tablas 2: Estudios revisados sobre gestión de residuos sólidos.

DATOS DE LA PUBLICACION

\begin{tabular}{|c|c|c|c|c|c|}
\hline 10. Autor & Año & \multicolumn{2}{|c|}{ Nombre de la Investigación } & $\begin{array}{c}\text { Revista donde su ubica la } \\
\text { publicación }\end{array}$ & Volumen y número \\
\hline $\begin{array}{l}\text { Vélez, Alberto } \\
\text { Germán; Peñafiel, } \\
\text { Pedro } \\
\text { Andrés; Heredia, } \\
\text { Marco; Barreno, } \\
\text { Stefany } \\
\text { Natali; Chávez, } \\
\text { Joselyn Fernanda. }\end{array}$ & (2019) & \multicolumn{2}{|c|}{$\begin{array}{l}\text { Propuesta de sistema de gestión de residuos sólidos } \\
\text { domésticos en la comunidad Waorani Gareno de la } \\
\text { Amazonía Ecuatoriana. }\end{array}$} & $\begin{array}{l}\text { https://dialnet.unirioja.es/servlet/arti } \\
\text { culo?codigo }=7563002\end{array}$ & $\begin{array}{l}\text { vol. 02, tomo 12, octubre } \\
2019 \text { pág. } 33-45\end{array}$ \\
\hline \multicolumn{6}{|c|}{ CONTENIDO DE LA PUBLICACION } \\
\hline $\begin{array}{l}\text { Tipo y Diseño de } \\
\text { Investigación }\end{array}$ & $\begin{array}{l}\text { Población y } \\
\text { Muestra }\end{array}$ & Instrumentos & $\begin{array}{l}\text { Aspectos } \\
\text { éticos }\end{array}$ & Resultados & Conclusión \\
\hline $\begin{array}{l}\text { Descriptivo, } \\
\text { propositivo. }\end{array}$ & $\begin{array}{l}1 \text { comunidad, } 32 \\
\text { viviendas, } 174 \\
\text { habitantes }\end{array}$ & $\begin{array}{l}\text { Entrevista, } \\
\text { encuesta }\end{array}$ & $\begin{array}{ll}\text { No conflicto } & \text { El estud } \\
\text { de interés } & \text { de eli } \\
& \text { metodol } \\
& \text { contribu } \\
& \text { al agua, } \\
& \text { repercus } \\
& \text { se debe } \\
& \text { gestión }\end{array}$ & $\begin{array}{l}\text { nciona que la población en la búsqueda } \\
\text { sus residuos sólidos emplean } \\
\text { tradicionales que lejos de ser una } \\
\text { ambiental son acciones contaminantes } \\
\text { o y aire, que en lo progresivo tendrá } \\
\text { n la salud de la comunidad; todo ello } \\
\text { falta de un sistema que integre a la } \\
\text { y a la comunidad. }\end{array}$ & $\begin{array}{l}\text { El estudio determinó que la } \\
\text { gestión de los RSU de la } \\
\text { comunidad en estudio } \\
\text { necesita de una propuesta } \\
\text { integral que proyecte } \\
\text { presentar beneficios entre la } \\
\text { comunidad y el medio } \\
\text { ambiente zonal, generando } \\
\text { ingresos económicos por la } \\
\text { comercialización de los } \\
\text { productos reciclados. }\end{array}$ \\
\hline
\end{tabular}

Ciencia Latina Revista Científica Multidisciplinar, Ciudad de México, México.

ISN 2707-2207 / ISSN 2707-2215 (en línea), julio-agosto, 2021, Volumen 5, Número 4. https://doi.org/10.37811/cl rcm.v5i4.765 p.6165 


\section{DATOS DE LA PUBLICACION}

\begin{tabular}{|c|c|c|c|c|c|c|c|}
\hline \multicolumn{2}{|l|}{ 11. Autor } & $\begin{array}{c}\mathbf{A} \tilde{\mathbf{n}} \\
\mathbf{0}\end{array}$ & \multicolumn{3}{|c|}{ Nombre de la Investigación } & Revista donde su ubica la publicación & Volumen y número \\
\hline \multicolumn{3}{|c|}{$\begin{array}{l}\text { Desouza, Caio Cezar } \\
\text { Ferreira; De Melo, Brenda } \\
\text { Rodrigues; Dos Santos, } \\
\text { Marcos Antônio } \\
\text { Souza; Rebello, Fabrício } \\
\text { Khoury; Martins, Cyntia } \\
\text { Meireles; et al. }\end{array}$} & \multicolumn{3}{|c|}{$\begin{array}{c}\text { Diagnóstico Da Sustentabilidade Na Gestão } \\
\text { De Resíduos Sólidos No Município De } \\
\text { Marituba, Região Metropolitana De Belém, } \\
\text { Estado Do Pará. }\end{array}$} & \multicolumn{2}{|c|}{$\begin{array}{c}\text { https://www.proquest.com/scholarly- } \\
\text { journals/diagnóstico-da-sustentabilidade-na-gestão- } \\
\text { de/docview/2384583887/se-2?accountid=37408 }\end{array}$} \\
\hline \multicolumn{8}{|c|}{ CONTENIDO DE LA PUBLICACION } \\
\hline $\begin{array}{l}\text { Tipo y Diseño de } \\
\text { Investigación }\end{array}$ & $\begin{array}{r}\text { Pobla } \\
\text { Mu }\end{array}$ & $\begin{array}{l}\text { ión y } \\
\text { stra }\end{array}$ & Instrumentos & $\begin{array}{l}\text { Aspectos } \\
\text { éticos }\end{array}$ & & Resultados & Conclusión \\
\hline $\begin{array}{c}\text { Aplicada, } \\
\text { propositiva }\end{array}$ & $1 \mathrm{mur}$ & cipio. & $\begin{array}{l}\text { Entrevista, } \\
\text { encuesta }\end{array}$ & $\begin{array}{l}\text { No conflicto } \\
\text { de interés }\end{array}$ & $\begin{array}{l}\text { Para aden } \\
\text { personas, } \\
\text { puede ser } \\
\text { En relaci } \\
\text { profesion } \\
\text { de obra lo } \\
\text { residuos } \\
\text { transporte } \\
\text { Los proce } \\
\text { recibido t: } \\
\text { la ciudad } \\
\text { Así, debic } \\
\text { en el mu } \\
\text { observaro } \\
\text { gases tóxi }\end{array}$ & $\begin{array}{l}\text { ás de garantizar la salud y el bienestar de las } \\
\text { el éxito de un sistema de gestión de residuos } \\
\text { una medida del éxito de la gobernanza. } \\
\text { on a esta dimensión, se destaca la falta de } \\
\text { les calificados en el municipio, ya que la mano } \\
\text { cal solo se utiliza en la etapa de recolección de } \\
\text { ólidos y el sostenimiento de los equipos de } \\
\text { solo se realiza a nivel local. } \\
\text { dimientos de gestión de residuos sólidos no han } \\
\text { anta atención en el proceso de planificación de } \\
\text { como otros sectores como el agua o la energía. } \\
\text { lo al mal manejo del relleno sanitario ubicado } \\
\text { nicipio, que pertenece al sector privado, se } \\
\text { n daños ambientales, como la dispersión de } \\
\text { cos y lixiviados, y daños a la salud pública. }\end{array}$ & $\begin{array}{l}\text { La aplicación de la matriz mostró } \\
\text { que el municipio de Marituba } \\
\text { presenta sostenibilidad media en } \\
\text { función al tratamiento adecuado de } \\
\text { residuos sólidos, sin embargo, se } \\
\text { notó la deficiencia de gestión } \\
\text { municipal sobre algunas } \\
\text { dimensiones analizadas. Los } \\
\text { aspectos que fueron fundamentales } \\
\text { refleja un nivel intermedio de } \\
\text { sostenibilidad y están asociados } \\
\text { fuertemente con las dimensiones } \\
\text { política y de conocimiento. Y los } \\
\text { aspectos donde se identificaron los } \\
\text { principales problemas están } \\
\text { relacionados con las dimensiones } \\
\text { tecnológicay económico-financiera. }\end{array}$ \\
\hline
\end{tabular}

Ciencia Latina Revista Científica Multidisciplinar, Ciudad de México, México.

ISN 2707-2207 / ISSN 2707-2215 (en línea), julio-agosto, 2021, Volumen 5, Número 4. https://doi.org/10.37811/cl rcm.v5i4.765 p.6166 


\section{DATOS DE LA PUBLICACION}

\begin{tabular}{|c|c|c|c|c|c|}
\hline 12. Autor & Año & \multicolumn{2}{|c|}{ Nombre de la Investigación } & $\begin{array}{c}\text { Revista donde su ubica la } \\
\text { publicación }\end{array}$ & Volumen y número \\
\hline $\begin{array}{l}\text { Sánchez Muñoz, } \\
\text { María Del } \\
\text { Pilar ; Cruz Cerón, } \\
\text { José } \\
\text { Gabriel ; Maldonado } \\
\text { Espinel, Paula } \\
\text { Carolina. }\end{array}$ & Gestiór & \multicolumn{3}{|c|}{$\begin{array}{l}\text { Gestión de residuos sólidos urbanos en América Latina: un } \\
\text { análisis desde la perspectiva de la generación }\end{array}$} & $\begin{array}{l}\text { vol. 2, Tomo. 11, Nov } \\
\text { 2020, pp. } \\
\text { 317-332 }\end{array}$ \\
\hline \multicolumn{6}{|c|}{ CONTENIDO DE LA PUBLICACION } \\
\hline $\begin{array}{l}\text { Tipo y Diseño de } \\
\text { Investigación }\end{array}$ & $\begin{array}{l}\text { Población y } \\
\text { Muestra }\end{array}$ & Instrumentos & $\begin{array}{l}\text { Aspectos } \\
\text { éticos }\end{array}$ & Resultados & Conclusión \\
\hline $\begin{array}{l}\text { Descriptiva, } \\
\text { correlacional }\end{array}$ & $\begin{array}{c}\text { Países de sud } \\
\text { américa, } 9 \text { países, } \\
\text { generación/hab. }\end{array}$ & Matriz de análisis & $\begin{array}{l}\text { La proyecc } \\
\text { a la aplica } \\
\text { los residu } \\
\text { reaprovech } \\
\text { proceso de } \\
\text { parte del c } \\
\text { estás políti } \\
\text { de la gener } \\
\text { donde se } \\
\text { acciones } \\
\text { disposiciór } \\
\text { sensato de }\end{array}$ & $\begin{array}{l}\text { n de las nuevas ciudades está orientada } \\
\text { on de nuevas tendencias de gestión de } \\
\text { sólidos entre ellas prevalece el } \\
\text { nientos de los residuos que mediante un } \\
\text { rminado pasaran a formar nuevamente } \\
\text { lo productivo, La implementación de } \\
\text { s tuvieron como objetivo la reducción } \\
\text { ión como es el caso de "Basura Cero", } \\
\text { gró comprobar que muchas de las } \\
\text { án direccionadas a las maneras de } \\
\text { y en pocas veces al comportamiento } \\
\text { población. }\end{array}$ & $\begin{array}{l}\text { Los mejores servicios de } \\
\text { gestión de residuos sólidos } \\
\text { urbanos en América Latina } \\
\text { dependerán de que las } \\
\text { administraciones } \\
\text { municipales fortalezcan su } \\
\text { capacidad de } \\
\text { respuesta al manejo de los } \\
\text { residuos. }\end{array}$ \\
\hline
\end{tabular}

\section{DATOS DE LA PUBLICACION}

Ciencia Latina Revista Científica Multidisciplinar, Ciudad de México, México.

ISN 2707-2207 / ISSN 2707-2215 (en línea), julio-agosto, 2021, Volumen 5, Número 4. https://doi.org/10.37811/cl rcm.v5i4.765 p.6167 


\begin{tabular}{lcccc}
\multicolumn{1}{c}{ 13. Autor } & Año & Nombre de la Investigación & $\begin{array}{c}\text { Revista donde su ubica la } \\
\text { publicación }\end{array}$ & \multicolumn{1}{c}{ Volumen y número } \\
\hline Gomes Mol, Marcos & $(2020)$ & Gestão adequada de resíduos sólidos como fator de proteção na & $10.26633 /$ RPSP.2020.22 \\
Paulo; Queiroz, & & ocorrência da dengue & vol.1, Tomo. 44, enero \\
Josiane T & & 51932 \\
Matos; Gomes, & & & 2020, \\
Júlia; Heller, Léo. & & & \\
\hline
\end{tabular}

\section{CONTENIDO DE LA PUBLICACION}

\begin{tabular}{|c|c|c|c|c|c|}
\hline $\begin{array}{l}\text { Tipo y Diseño de } \\
\text { Investigación }\end{array}$ & Población y Muestra & Instrumentos & $\begin{array}{l}\text { Aspectos } \\
\text { éticos }\end{array}$ & Resultados & Conclusión \\
\hline $\begin{array}{c}\text { Exploratorio, } \\
\text { cuantitativo e } \\
\text { transversa }\end{array}$ & $\begin{array}{c}1 \text { estado, } 853 \\
\text { municipalidades. }\end{array}$ & & & $\begin{array}{l}\text { El estudio reflejó que no hubo asociación entre el } \\
\text { manejo de desechos sólidos y la incidencia de } \\
\text { Chikungunya y Zika. asu vez la incidencia del } \\
\text { dengue se asoció con el manejo de residuos sólidos } \\
\text { y mostró una relación inversa significativa con el } \\
\text { porcentaje de vulnerables a la pobreza, esto sugiere } \\
\text { que cuanto menor es la cobertura de recolección de } \\
\text { selectivo, mayores fueron los casos registrados de } \\
\text { dengue. }\end{array}$ & $\begin{array}{l}\text { El inadecuado manejo de } \\
\text { residuos sólidos influye en } \\
\text { los casos de enfermedades } \\
\text { infecciosas como el dengue, } \\
\text { por lo tanto, se debe tener en } \\
\text { cuenta el grado de la } \\
\text { incidencia y vulnerabilidad } \\
\text { de las enfermedades frente a } \\
\text { la comunidad para ser } \\
\text { considerado como una } \\
\text { prioridad de salud pública } \\
\text { para un correcto } \\
\text { tratamiento. }\end{array}$ \\
\hline
\end{tabular}




\begin{tabular}{lcccc}
\multicolumn{1}{c}{ 14. Autor } & $\begin{array}{c}\text { Añ } \\
\mathbf{0}\end{array}$ & Nombre de la Investigación & Revista donde su ubica la publicación \\
\hline Alejandro Rodríguez & $(20$ & Transparencia y economía circular: análisis y & http://dx.doi.org/10.7203/CIRIEC-E.99.16011 & vol. 99, noviembre 2020, pág. \\
Martín, Ricardo Palomo & $20)$ & valoración de la gestión municipal de los residuos & \\
$\begin{array}{l}\text { Zurdo, Francisco } \\
\text { González-Sánchez }\end{array}$ & & sólidos urbanos. & \\
\hline
\end{tabular}

\section{CONTENIDO DE LA PUBLICACION}

\begin{tabular}{|c|c|c|c|c|c|}
\hline $\begin{array}{l}\text { Tipo y Diseño de } \\
\text { Investigación }\end{array}$ & $\begin{array}{c}\text { Población y } \\
\text { Muestra }\end{array}$ & Instrumentos & $\begin{array}{l}\text { Aspectos } \\
\text { éticos }\end{array}$ & Resultados & Conclusión \\
\hline $\begin{array}{l}\text { Transversal } \\
\text { causal, } \\
\text { propositiva }\end{array}$ & $\begin{array}{c}96 \\
\text { municipalidades,20. } \\
\text { 416.034 habitantes. }\end{array}$ & Cuestionario & $\begin{array}{l}\text { No conflicto } \\
\text { de interés }\end{array}$ & $\begin{array}{l}\text { El estudio refleja que los ayuntamientos con } \\
\text { poblaciones mayores a } 500.000 \text { habitantes, son más } \\
\text { transparentes en su gestión, así también se rescata que } \\
2 \text { de las ITMGR, presentan resultados poco } \\
\text { alentadores sobre el tratamiento y recojo de los } \\
\text { residuos sólidos, tres de las CCAA son las que } \\
\text { muestran datos referenciales en cuanto al reciclado y } \\
\text { recolección selectiva de los residuos sólidos. }\end{array}$ & $\begin{array}{l}\text { Se destaca la publicación de la } \\
\text { información referente a la de } \\
\text { gestión de los RSU a través de } \\
\text { los portales de transparencia } \\
\text { web municipal, centrando la } \\
\text { atención en los objetos de } \\
\text { evaluación del ITA, } \\
\text { previamente conocidos. }\end{array}$ \\
\hline
\end{tabular}

\section{DATOS DE LA PUBLICACION}

\begin{tabular}{|c|c|c|c|c|}
\hline 15. Autor & Año & Nombre de la Investigación & $\begin{array}{c}\text { Revista donde su ubica la } \\
\text { publicación }\end{array}$ & Volumen y número \\
\hline $\begin{array}{l}\text { Katty Coral } \\
\text { Carrillo; Jorge Oviedo } \\
\text { Costales; Ana } \\
\text { Rodríguez Machado. }\end{array}$ & $(2021)$ & $\begin{array}{l}\text { Energía a partir de residuos sólidos urbanos, caso } \\
\text { parroquia Limoncocha en la Amazonía ecuatoriana. }\end{array}$ & $\begin{array}{c}\text { http://dx.doi.org/10.32719/25506641.2 } \\
021.9 .9\end{array}$ & $\begin{array}{l}\text { núm. 09, febrero } 2021 \text { pág. } \\
216-236\end{array}$ \\
\hline
\end{tabular}

Ciencia Latina Revista Científica Multidisciplinar, Ciudad de México, México.

ISN 2707-2207 / ISSN 2707-2215 (en línea), julio-agosto, 2021, Volumen 5, Número 4. https://doi.org/10.37811/cl rcm.v5i4.765 p.6169 


\section{CONTENIDO DE LA PUBLICACION}

\begin{tabular}{|c|c|c|c|c|c|}
\hline $\begin{array}{l}\text { Tipo y Diseño de } \\
\text { Investigación }\end{array}$ & $\begin{array}{c}\text { Población y } \\
\text { Muestra }\end{array}$ & Instrumentos & $\begin{array}{l}\text { Aspectos } \\
\text { éticos }\end{array}$ & Resultados & Conclusión \\
\hline $\begin{array}{c}\text { Descriptivo } \\
\text { inductivo-deductivo. }\end{array}$ & 874 personas & $\begin{array}{l}\text { Guía de } \\
\text { observación, Lista } \\
\text { de chequeo }\end{array}$ & $\begin{array}{l}\text { No conflicto } \\
\text { de interés }\end{array}$ & $\begin{array}{l}\text { El estudio estuvo basado en el aprovechamiento } \\
\text { energético de los residuos sólidos, excluyendo } \\
\text { aquellos que no presentan energía calórica, en las } \\
\text { pruebas desarrolladas se logró deducir que muchos de } \\
\text { los residuos son quemados a cielo abierto ocasionado } \\
\text { contaminación ambiental y disturbios en los visitantes, } \\
\text { así también se corrobora que los residuos que } \\
\text { mantienen en su composición elementos de madera y } \\
\text { textiles son los que producen mayor calor, y el papel } \\
\text { se encuentra por debajo de los mencionados esto } \\
\text { debido a la variedad de residuos que involucra esta } \\
\text { categoría y a las diferentes disposiciones de esta } \\
\text { tipología de RSU. }\end{array}$ & 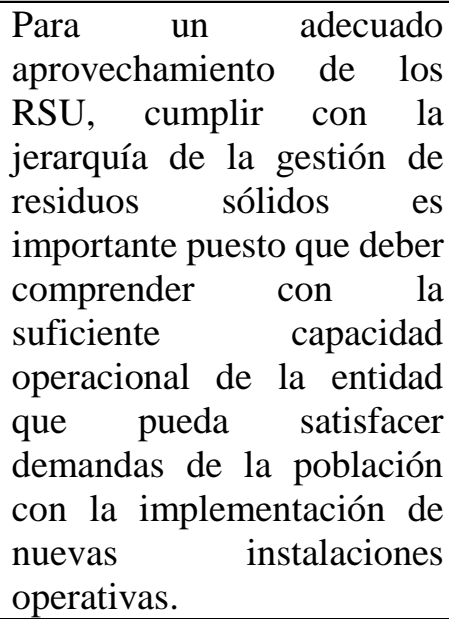 \\
\hline
\end{tabular}

\section{DATOS DE LA PUBLICACION}

\begin{tabular}{|c|c|c|c|c|}
\hline 16. Autor & Año & Nombre de la Investigación & $\begin{array}{l}\text { Revista donde su ubica la } \\
\text { publicación }\end{array}$ & Volumen y número \\
\hline $\begin{array}{l}\text { Gutiérrez, } \\
\text { Jackson Erminzul } \\
\text { Monroy; Ochoa, } \\
\text { Martha Liliana } \\
\text { Díaz; Guarnizo, } \\
\text { María Claudia } \\
\text { Vera; Gutiérrez, } \\
\text { Luis Miguel } \\
\text { Monroy. }\end{array}$ & $(2021)$ & $\begin{array}{l}\text { Diseño de acopio temporal para clasificación y manejo de } \\
\text { residuos sólidos ordinarios aplicando sistemas }\end{array}$ & $\begin{array}{l}\text { https://www.proquest.com/scholarly- } \\
\text { journals/diseño-de-acopio-temporal- } \\
\text { para-clasificación- } \\
\text { y/docview/2483100993/se- } \\
2 \text { ?accountid=37408 }\end{array}$ & $\begin{array}{l}\text { Ed. 09, marzo } 2021 \text { pág. } \\
285-296\end{array}$ \\
\hline
\end{tabular}

Ciencia Latina Revista Científica Multidisciplinar, Ciudad de México, México.

ISN 2707-2207 / ISSN 2707-2215 (en línea), julio-agosto, 2021, Volumen 5, Número 4. https://doi.org/10.37811/cl rcm.v5i4.765 p.6170 


\section{CONTENIDO DE LA PUBLICACION}

\begin{tabular}{|c|c|c|c|c|c|}
\hline $\begin{array}{l}\text { Tipo y Diseño de } \\
\text { Investigación }\end{array}$ & Población y Muestra & Instrumentos & $\begin{array}{l}\text { Aspectos } \\
\text { éticos }\end{array}$ & Resultados & Conclusión \\
\hline $\begin{array}{l}\text { No experimental - } \\
\text { documental }\end{array}$ & $\begin{array}{l}2281 \text { habitantes, } 456 \\
\text { corresponden a la zona } \\
\text { urbana y } 1825 \text { a la } \\
\text { zona rural. }\end{array}$ & $\begin{array}{l}\text { Revisión } \\
\text { Bibliográfica }\end{array}$ & $\begin{array}{l}\text { No conflicto } \\
\text { de interés }\end{array}$ & $\begin{array}{l}\text { La utilización de productos de plástico causa } \\
\text { alteración en el medio ambiente desde la generación } \\
\text { de la misma hasta el proceso de disposición final, } \\
\text { Por lo que, al realizar campañas de mitigación, } \\
\text { sensibilización, capacitación ambiental, aseguramos } \\
\text { una correcta segregación de los residuos sólidos en los } \\
\text { primeros actores intervinientes que son la población, } \\
\text { pues estas acciones son fundamentales en los procesos } \\
\text { de adaptación a nuevos cambios del sistema de gestión } \\
\text { integral, es así como la estación ECA funciona de } \\
\text { manera idónea, donde se trabaja con énfasis la } \\
\text { mitigación del impacto ambiental. }\end{array}$ & $\begin{array}{l}\text { El engrandecimiento } \\
\text { eminente de la generación } \\
\text { de residuos sólidos por parte } \\
\text { de la población, } \\
\text { y la falta de centros de } \\
\text { acopio o instalaciones } \\
\text { dedicadas a la selección, } \\
\text { clasificación de residuos } \\
\text { sólidos ocasiona que se siga } \\
\text { disponiendo en botaderos } \\
\text { municipales los cuales no } \\
\text { presentan control alguno en } \\
\text { el ámbito de salubridad, y } \\
\text { por tanto no permite el } \\
\text { aprovechamiento de } \\
\text { recursos reaprovecharles } \\
\text { para la transformación, pues } \\
\text { la ausencia de actividades } \\
\text { formales aumenta } \\
\text { constantemente de manera } \\
\text { acelerada una mayor } \\
\text { contaminación ambiental. }\end{array}$ \\
\hline
\end{tabular}

\section{DATOS DE LA PUBLICACION}

Ciencia Latina Revista Científica Multidisciplinar, Ciudad de México, México.

ISN 2707-2207 / ISSN 2707-2215 (en línea), julio-agosto, 2021, Volumen 5, Número 4. https://doi.org/10.37811/cl rcm.v5i4.765 p.6171 


\begin{tabular}{|c|c|c|c|c|}
\hline & Año & Nombre de la Investigación & $\begin{array}{c}\text { Revista donde su ubica la } \\
\text { publicación }\end{array}$ & Volumen y número \\
\hline $\begin{array}{l}\text { Ortiz-Pech, } \\
\text { Rafael; Burgos- } \\
\text { Suárez, Lucelly } \\
\text { Carolina; Alba }\end{array}$ & $(2020)$ & $\begin{array}{l}\text { Generación, reciclaje y disposición final de los principales } \\
\text { residuos en México, 2000-2014 }\end{array}$ & $\begin{array}{l}\text { https://www.proquest.com/scholarly- } \\
\text { journals/generación-reciclaje-y- } \\
\text { disposición-final-de- } \\
\text { los/docview/2436140884/se- }\end{array}$ & $\begin{array}{l}\text { vol. 01, tomo 23, agosto } \\
\text { 2020, pág. 01-24 }\end{array}$ \\
\hline $\begin{array}{l}\text { Rosa Rivera-de la } \\
\text { Rosa. }\end{array}$ & & & 2 ? accountid $=37408$ & \\
\hline
\end{tabular}

\begin{tabular}{|c|c|c|c|c|c|}
\hline \multicolumn{6}{|c|}{ CONTENIDO DE LA PUBLICACION } \\
\hline $\begin{array}{l}\text { Tipo y Diseño de } \\
\text { Investigación }\end{array}$ & Población y Muestra & Instrumentos & $\begin{array}{l}\text { Aspectos } \\
\text { éticos }\end{array}$ & Resultados & Conclusión \\
\hline $\begin{array}{c}\text { No experimental- } \\
\text { documental }\end{array}$ & $\begin{array}{l}117.300 .000 \\
\text { habitantes }\end{array}$ & $\begin{array}{l}\text { Guía de } \\
\text { observación }\end{array}$ & $\begin{array}{l}\text { No conflicto } \\
\text { de interés }\end{array}$ & $\begin{array}{l}\text { El estado de determnados residuos importantes como } \\
\text { el material orgánico, papel y cartón, vidrio, plásticos } \\
\text { PET y otros (RSU), comienza desde el consumo de los } \\
\text { hogares gracias a un ingreso monetario mayor, } \\
\text { generan residuos que se pueden reciclar y otro tanto } \\
\text { pueden terminar en sitios controlados o rellenos } \\
\text { sanitarios como su disposición final. Para los RME y } \\
\text { los RP, siguen un patrón similar, pero requiere mayor } \\
\text { complejidad su reciclaje, al igual que la existencia de } \\
\text { información detallada y actualizada. }\end{array}$ & $\begin{array}{l}\text { La investigación mostra que } \\
\text { la generación de algunos } \\
\text { residuos se acrecienta } \\
\text { mientras que el reciclaje se } \\
\text { mantiene constante, } \\
\text { creciente o decreciente con } \\
\text { el pasar del tiempo. En } \\
\text { cuanto al incremento de los } \\
\text { residuos sólidos urbanos } \\
\text { (RSU) más importantes, } \\
\text { se debe al aumento de la } \\
\text { población, que provoca } \\
\text { mayor consumo y por tanto } \\
\text { mayor producción de } \\
\text { satisfactores. }\end{array}$ \\
\hline
\end{tabular}




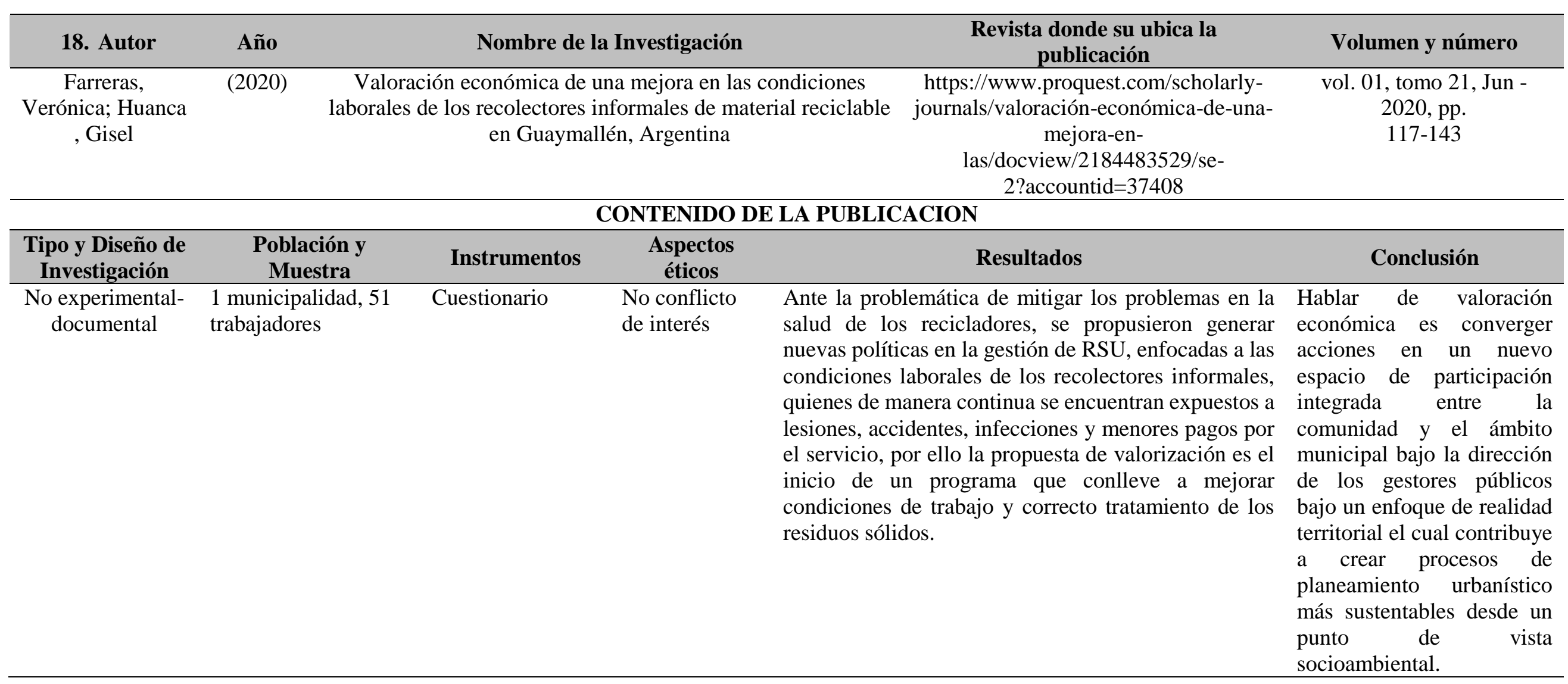




\begin{tabular}{lcccc}
\multicolumn{1}{c}{ 19. Autor } & Año & Nombre de la Investigación & $\begin{array}{c}\text { Revista donde su ubica la } \\
\text { publicación }\end{array}$ \\
\hline Teresa & $(2019)$ & $\begin{array}{c}\text { Propuesta Metodológica Para el Sistema de Gestión de los } \\
\text { Margarita Cárden }\end{array}$ & Residuos Sólidos Urbanos en Villa Clara & Volumen y número \\
as-Ferrer, Ana & & & \\
Margarita & & & \\
Contredalyc.org/articulo.oa?i & & & vol. 39, núm. 2, Agosto 2019, pág. \\
Ronaldo & & & \\
Francisco Santos- & & & \\
Herrero & & & \\
\hline
\end{tabular}

\section{CONTENIDO DE LA PUBLICACION}

\begin{tabular}{|c|c|c|c|c|c|}
\hline $\begin{array}{l}\text { Tipo y Diseño de } \\
\text { Investigación }\end{array}$ & Población y Muestra & Instrumentos & $\begin{array}{l}\text { Aspectos } \\
\text { éticos }\end{array}$ & Resultados & Conclusión \\
\hline $\begin{array}{l}\text { No experimental, } \\
\text { propositivo }\end{array}$ & $\begin{array}{l}2281 \text { habitantes, } 456 \\
\text { corresponden a la } \\
\text { zona urbana y } 1825 \text { a } \\
\text { la zona rural. }\end{array}$ & $\begin{array}{l}\text { Revisión } \\
\text { Bibliográfica }\end{array}$ & $\begin{array}{l}\text { No conflicto } \\
\text { de interés }\end{array}$ & $\begin{array}{l}\text { Una correcta sectorización propicia el uso efectivo de los } \\
\text { recursos operativos, es por ello que en la zona de Santa } \\
\text { Clara la utilización del método de contenedores y la del } \\
\text { algoritmo del agente viajero, precisó la ruta óptima para el } \\
\text { camión recolecto de manera asertiva al módulo Network } \\
\text { Modeling enlazado al software WinQSB, esto produjo el } \\
\text { ahorro de horas hombre, horas máquina, llantas, } \\
\text { combustible y sobre todo minimización de gases } \\
\text { contaminantes al medio ambiente, }\end{array}$ & $\begin{array}{l}\text { El sistema actual de manejo } \\
\text { de Residuos Sólidos } \\
\text { Urbanos en Santa Clara no } \\
\text { responde a las necesidades } \\
\text { ambientales, sanitarias y } \\
\text { legales de la población al } \\
\text { que se le debe prestar el } \\
\text { servicio, siendo las } \\
\text { principales deficiencias } \\
\text { detectadas en la no } \\
\text { segregación, en el origen de } \\
\text { las mismas, mala } \\
\text { manipulación de desechos y } \\
\text { recolección, ineficiente } \\
\text { procedimiento en el } \\
\text { botadero municipal y falta } \\
\text { de educación en general. }\end{array}$ \\
\hline
\end{tabular}




\begin{tabular}{|c|c|c|c|c|}
\hline 20. Autor & Año & Nombre de la Investigación & $\begin{array}{l}\text { Revista donde su ubica la } \\
\text { publicación }\end{array}$ & Volumen y número \\
\hline $\begin{array}{c}\text { Egon } \\
\text { Montecinos, } \\
\text { Víctor Neira, } \\
\text { Guillermo Díaz, } \\
\text { James Park }\end{array}$ & (2019) & $\begin{array}{c}\text { Gobernanza democrática, descentralización y territorio: } \\
\text { Análisis del plan Chiloé en Chile }\end{array}$ & $\begin{array}{c}\text { https://doi.org/10.29092/uacm.v16i4 } \\
1.753\end{array}$ & $\begin{array}{l}\text { vol. 16, núm. 41, diciembre 2019, } \\
\text { pp. } \\
413-436\end{array}$ \\
\hline
\end{tabular}

\section{CONTENIDO DE LA PUBLICACION}

\begin{tabular}{|c|c|c|c|c|c|}
\hline $\begin{array}{l}\text { Tipo y Diseño de } \\
\text { Investigación }\end{array}$ & $\begin{array}{c}\text { Población y } \\
\text { Muestra }\end{array}$ & Instrumentos & $\begin{array}{l}\text { Aspectos } \\
\text { éticos }\end{array}$ & Resultados & Conclusión \\
\hline $\begin{array}{l}\text { No experimental, } \\
\text { propositivo }\end{array}$ & $\begin{array}{l}25 \text { artículos } \\
\text { científicos. }\end{array}$ & $\begin{array}{l}\text { Revisión } \\
\text { Bibliográfica }\end{array}$ & $\begin{array}{l}\text { No conflicto } \\
\text { de interés }\end{array}$ & $\begin{array}{l}\text { La clave de la gobernanza yace en saber organizar los } \\
\text { espacios públicos deliberativos basados en normas } \\
\text { procedimentales que retroalimenten la confianza en la } \\
\text { estructura de interdependencia. Nadie tiene el conocimiento } \\
\text { suficiente para resolver unilateralmente cuestiones } \\
\text { complejas y los límites de nuestro conocimiento nos obligan } \\
\text { a interactuar para buscar soluciones provisionales siguiendo } \\
\text { procedimientos que nos permitan aprender permanentemente } \\
\text { y adaptarnos. }\end{array}$ & $\begin{array}{l}\text { La decisión del plan } \\
\text { Chiloé posee un valor } \\
\text { estratégico que consiste en } \\
\text { intentar configurar un } \\
\text { nuevo modelo de gestión, } \\
\text { no formalizado en la } \\
\text { institucionalidad } \\
\text { descentralizada de Chile. } \\
\text { El principal } \\
\text { valor es poseer un modelo } \\
\text { centrado en la demanda } \\
\text { territorial como eje } \\
\text { determinante de la oferta } \\
\text { pública territorial. }\end{array}$ \\
\hline
\end{tabular}

Ciencia Latina Revista Científica Multidisciplinar, Ciudad de México, México.

ISN 2707-2207 / ISSN 2707-2215 (en línea), julio-agosto, 2021, Volumen 5, Número 4. https://doi.org/10.37811/cl rcm.v5i4.765 p.6175 


\section{DATOS DE LA PUBLICACION}

\begin{tabular}{|c|c|c|c|c|}
\hline 21. Autor & Año & Nombre de la Investigación & $\begin{array}{l}\text { Revista donde su ubica la } \\
\text { publicación }\end{array}$ & Volumen y número \\
\hline $\begin{array}{l}\text { Esteban Salazar- } \\
\text { Acuña }\end{array}$ & $(2020)$ & $\begin{array}{l}\text { Indicador económico para la evaluación de la gestión } \\
\text { municipal de los residuos valorizables en Costa Rica }\end{array}$ & $\begin{array}{l}\text { https://www.scielo.sa.cr/scielo.php?s } \\
\text { cript=sci_arttext\&pid=S2215- } \\
38962020000100001\end{array}$ & vol: 5 \\
\hline
\end{tabular}

\begin{tabular}{|c|c|c|c|c|c|}
\hline \multicolumn{6}{|c|}{ CONTENIDO DE LA PUBLICACION } \\
\hline $\begin{array}{l}\text { Tipo y Diseño de } \\
\text { Investigación }\end{array}$ & $\begin{array}{l}\text { Población y } \\
\text { Muestra }\end{array}$ & Instrumentos & $\begin{array}{l}\text { Aspectos } \\
\text { éticos }\end{array}$ & Resultados & Conclusión \\
\hline $\begin{array}{l}\text { No experimental, } \\
\text { propositivo }\end{array}$ & $\begin{array}{c}1 \text { cuidad, } 24000 \\
\text { habitantes. }\end{array}$ & $\begin{array}{l}\text { Revisión } \\
\text { Bibliográfica }\end{array}$ & $\begin{array}{l}\text { No conflicto } \\
\text { de interés }\end{array}$ & $\begin{array}{l}\text { Con la finalidad de minimizar costos operativos y el pago por } \\
\text { el servicio de recojo de los residuos sólidos municipales la } \\
\text { IA es considerado como un indicador de carácter remanente } \\
\text { en los procesos de inversión municipal enfocado al ahorro en } \\
\text { la fase de disposición final y la generación de nuevos } \\
\text { capitales económicos basado en la recuperación de residuos } \\
\text { aprovechables en escala local. }\end{array}$ & $\begin{array}{l}\text { En base al estudio } \\
\text { realizado en posible } \\
\text { establecer conjeturas } \\
\text { basadas en la inversión } \\
\text { sobre residuos que tienen } \\
\text { valor económico en el } \\
\text { mercado, con propósitos } \\
\text { de sostenibilidad, } \\
\text { existiendo en la actualidad } \\
\text { una deficitaria acción e } \\
\text { intervención de los } \\
\text { gestores locales para } \\
\text { priorizar los procesos de } \\
\text { recuperación, valorización } \\
\text { y transformación de los } \\
\text { residuos, por el alto costo } \\
\text { que estos demandan. }\end{array}$ \\
\hline
\end{tabular}

Ciencia Latina Revista Científica Multidisciplinar, Ciudad de México, México. 


\section{DISCUSIÓN}

La revisión sistemática refleja los aciertos sobre diversos estudios respecto a los procesos gubernamentales en latino América, que refieren nuevos enfoques sobre la gobernanza, sobre permitir que los gobiernos inicien acciones de colaboración con los diversos actores que se encuentran fuera del sistema público, manteniendo siempre el principio fundamental de atención a la sociedad sustentado mediante el uso adecuado de los recursos en las rendiciones de cuenta, a ello se adiciona en la necesidad de apoyarse en la las nuevas tecnologías, por ello su gestión propicia que los gobernantes, la ciudadanía, las empresas y otros actores implicados en los municipios, propicien una mirada transversal direccionada a la gestión de herramientas tecnológica en el ámbito municpal y hacer que los servicios puedan generarse de manera eficiente tal como menciona Longo, (2020), ante ello contar con el recurso humano idóneo y comprometido, donde aportan con sus capacidades en el cumplimiento de objetivos y logros de metas por los gobiernos subnacionales, siendo este término el más empleado por el Banco Mundial; en ese sentido, el recurso humano es considerado como imput (insumo) en los diferentes procesos que desarrolla la gestión municipal donde no solamente articula procesos, si no también se relaciona con la ciudadanía, siendo capaz de escuchar y canalizar sus necesidades y convertirlo en la generación de valor público para la gestión edil, existiendo una confusión en cuanto a las misión organizacional estatal en cuanto a la acción burocrática y administrativa que ponen límites a las actuaciones propias de las organizaciones, las cuales debería pasar por la reconceptualización e importantes cambios normativos, organizativos y metodológicos facilitando la interpretación de necesidades, como indica (López , 2018).

En relación al tema de estudio abordado existen innumerables explicaciones para concordar con la aseveración de estar ante la posibilidad de un colapso estructural, asumiéndolo como una oportunidad de proponer una reforma del Sistema estatal concordando con el escrito de Gonzales, Leal y Martínez (2019) quienes mencionan que defender un hecho dinámico para identificar las problemáticas del entorno sobre las problemáticas de la organización y empezar a generar cambios que generen ventajas en los resultados que plantea la organización como parte de sus procesos. corroborando también lo descrito por Teixeira (2018) quien refiere que la gran parte de municipios locales no afilian destrezas de gobernanza analógica que faciliten los procesos de gestión 
como parte fundamental de los procesos gubernamentales municipales. En ese sentido, muchos estudios concluyeron que la estructura prestacional de servicios debe ser abordado para generar una nueva propuesta prestacional de servicio, mostrando la agilidad en poder responder las necesidades de los ciudadanos. Esta reforma estructural debe ser prioritario en dar soluciones emergentes, en donde pueda contextualizar a la realidad, en donde la oferta pueda alcanzar una mayor cobertura de las necesidades de los ciudadanos.

El punto de vista social sustentable muestra una adecuada gestión de residuos sólidos asegura el bienestar de la comunidad en cuanto a salud, puesto que se minoriza las posibles afectaciones a la misma por problemas de contaminación ambiental y la presencia de agentes de transmisión de enfermedades infecciosas generan una alta probabilidad de producir una epidemia, tal como lo mencionan Gomes, Queiroz, Gomes, \& Heller (2020). Por tanto, el bienestar de las personas y la comunidad en general, tiene una estrecha relación entre la adecuada gestión de RSU, y los procesos que forman parte del sistema institucional llevado a cabo en las entidades locales correspondientes desde el planeamiento, el uso de recursos, procedimientos admirativos y otros que involucre la correcta gestión pública, así lo refieren Desouza, y otros (Desouza, y otros, 2019).

En relación al uso adecuado de los capitales institucionales contar con una adecuada logística y área operativa para la recolección de los residuos sólidos es básico, puesto que se debe planificar acciones de zonificación, métodos de recolección, rutas óptimas de recojo, para optimizar el recurso económico y material, puesto que generaría menores gastos en ambos aspectos generando un menor impacto en el ambiente por la continua utilización de compactadoras que generan combustión por hidrocarburos y contaminan el aire, tal como lo mencionan (Cárdenas, Contreras , \& Santos, 2019) en su estudio realizado.

\section{CONCLUSIONES.}

Los estudios de mayor predominancia en la revisión sistemática son básicos, con diseño descriptivos sumado a estudios comparativos y propositivos, la revisión sistemática, se sustentó en la gestión de procesos gubernamentales y la prestación de servicios en la gestión de residuos sólidos; la primera variable es determinante para conocer los procesos gubernamentales que intervienen en la gestión del gobierno local a fin de efectivizar los resultados esperados como lo son el cumplimiento de metas para obtener los incentivos, 
en tanto gestionar adecuadamente los procesos gubernamentales en la gestión local, buscando responder adecuadamente a la demanda poblacional, que incorpora diferentes miradas, entre ellas la social, económica, medio ambiental e institucional.

De la misma manera, los investigadores precisan que mejorar las condiciones institucionales, principalmente en su la estructura y funcionalidad, puede generar cambios fundamentales para la reestructuración organizacional, que facilitara el acercamiento entre el gobierno y la ciudadanía, esto estudios advierten que el manejo de una buena logística ayudará que el servicio operativo sea más eficiente, utilizando los recursos económicos y maquinaria que acrediten la correcta gestión de los residuos sólidos, y al mismo tiempo generar un valor en el cual se genere la participación ciudadana como un eje principal de las cadenas de valor económico integrado que se puede establecer entre los gobiernos locales y los ciudadanos, en tanto existen investigaciones que revelan que gestionar bajo los nuevos conceptos de gobernanza y gobernabilidad aplicado a las nueva estrategias funcionales del dinamismo organizacional en la gestión púbica, conlleva a optimizar los procesos en las distintas áreas de los gobiernos locales, apertura nuevas ideas de aprovechamiento de residuos sólidos para generar una dinamismo operativo estere los gestores municipales, parte operativa, y miembros de salud, pues el enfoque propone aminorar las enfermedades infecciosas casadas por agentes de transmisión que afecta en mayor cantidad a las poblaciones de las zonas periféricos de la ciudad, pues generar una visión de reaprovechamiento de recursos sólidos que pueden ser integrados a una cadena de transformación en una economía circular sostenible en el tiempo con la sociedad y el medio ambiente es una nueva alternativa de generar y encontrar valor en los RS.

\section{REFERENCIAS BIBLIOGRAFICAS}

Alejandro Rodríguez-Martín, R. P.-Z.-S. (Julio de 2020). Transparencia y economía circular: análisis y valoración de la gestión municipal de los residuos sólidos urbanos. Anonymous.CIRIEC - Espana, 99, $233 \quad-272$. doi:http://dx.doi.org/10.7203/CIRIEC-E.99.16011

Ana Verónica Polack, S. M. (2019). Las asociaciones público-privadas como instrumento de gobernanza colaborativa: apuntes para el debate y retos para la gestión. Políticas públicas y desarrollo, 21(43), 191-205. doi:10.29375/01240781.3730 
Cárdenas Ferrer, T. M., Contreras Moya, A. M., \& Santos Herrero, R. F. (2019). Propuesta Metodológica Para el Sistema de Gestión de los Residuos Sólidos Urbanos en Villa Clara. Tecnología Química, 39(2), 471-488. Obtenido de http://www.redalyc.org/articulo.oa?id=445559634015

Carrillo, K. C., Costales, J. O., \& Machado., A. R. (2021). Energía a partir de residuos sólidos urbanos, caso parroquia Limoncocha en la Amazonía ecuatoriana. $\begin{array}{llllll}\text { Estudios de } & \text { da } & \text { Gestión, } & \text { 09, } & 216 & -236 .\end{array}$ doi:http://dx.doi.org/10.32719/25506641.2021.9.9

Coral Carrillo , K., Oviedo Costales , J., \& Rodríguez Machado , A. (2021). Energía a partir de residuos sólidos urbanos, caso parroquia Limoncocha en la Amazonía ecuatoriana. Estudios de la Gestión, 1(9), $215 \quad-236$. doi:https://doi.org/10.32719/25506641.2021.9.9

Daniel Javier De la Garza Montemayor, E. R. (enero de 2018). Tendencias en la administración pública moderna: la nueva gestión pública en México. Revista Venezolana de Gerencia, 23(81), 31-48. doi:https://www.redalyc.org/articulo.oa? id $=29055767003$

Desouza, C. C., De Melo, B. R., Dos Santos, M. A., Rebello, F. K., Martins, C. M., \& al., e. (abril de 2019). Diagnóstico da sustentabilidade na gestão de resíduos sólidos no município de Marituba, região metropolitana de Belém, estado do Pará. Revista Metropolitana de Sustentabilidade, 02, $115 \quad$ - 136. doi:revistaseletronicas.fmu.br/index.php/rms

Egon Montecinos, V. N. (Diciembre de 2019). Gobernanza democrática, descentralización y territorio: Análisis del plan Chiloé en Chile. Andamios, 16(41), 413-436. doi:https://doi.org/10.29092/uacm.v16i41.753

Farreras, V., \& Huanca, G. (Junio de 2020). Valoración económica de una mejora en las condiciones laborales de los recolectores informales de material reciclable en Guaymallén, Argentina. Trabajo Socia, 117-143. doi:http://dx.doi.org/10.15446/ts.v21n1.70327

Gomes Mol, M. P., Queiroz, J. T., Gomes, J., \& Heller, L. (2020). Gestão adequada de resíduos sólidos como fator de proteção na ocorrência da dengue. Revista Panamericana de Salud Pública, 44(01), 1. doi:10.26633/RPSP.2020.22 
Gonzáles Gonzáles, A., Leal Rodriguez, L., \& Martínez Caballero, D. (2019). Herramientas para la gestión por procesos. Cuadernos Latinoamericanos de Administración, 15(28), 01-012. doi:https://www.redalyc.org/articulo.oa? $\mathrm{id}=409659500003$

Gutiérrez, J. E., Ochoa, M. L., Guarnizo, M. C., \& Gutiérrez, L. M. (2021). Diseño de acopio temporal para clasificación y manejo de residuos sólidos ordinarios aplicando sistemas. Revista Ibérica de Sistemas e Tecnologias de Informação, 9, 285 -296. doi:https://www.proquest.com/scholarly-journals/diseño-de-acopiotemporal-para-clasificación-y/docview/2483100993/se-2?accountid=37408

Herbert Cristhiano Pinheiro de Andrade, A. M. (2018). Coproducción e Incidencia de la Sociedad Civil en la Política de Residuos Sólidos en Belém, Amazonia. Administração Pública e Gestão Social, $12(2), \quad 1-16$. doi:https://www.redalyc.org/articulo.oa? id=351562414011

Juedir Viana Teixeira, A. A. (2018). Índices de transparencia y gestión en las entidades p\{ublicas como herramientas de control y desempeño_ Una comparación entre indicadore municipales en Alagoas - Brasil. Revista Científica "Visión de Futuro", 32(1), 75-90. doi:https://www.redalyc.org/articulo.oa? id=357959548005

Kumar Ponnusamy, S., Sunita J. , V., Saravanan, A., \& Yaashikaa, P. (Agosto de 2019). Avances en la producción y aplicación de biocarbón a partir de materias primas lignocelulósicas para la remediación de contaminantes ambientales. Tecnología Bioambiental, 292. doi:DOI: 10.1016 / j.biortech.2019.122030

Longo, F. (2020). Gobernanza pública para la innovación. Revista del CLAD Reforma y Democracia(76), 1315-2378. Obtenido de https://www.redalyc.org/articulo.oa?id=357565951002

López-Cabanas, M. (2018). Servicios sociales municipales. Necesidad de una refundación. Papeles del Psicólogo, 39(02), 1-11. doi:ISSN : 1886-1415

Mariela Cuadro. (2020). Lo internacional y lo global. Gubernamentalidad global: analítica y práctica de gobierno. Colombia Internacional(102), 23-39. doi:https://doi.org/10.7440/colombiaint102.2020.02

Monroy Gutiérrez, J. E., Díaz Ochoa, M. L., Vera Guarnizo, M. C., \& Monroy Gutiérrez, L. M. (2021). Diseño de acopio temporal para clasificación y manejo de residuos sólidos ordinarios aplicando sistemas. Revista Ibérica de Sistemas e Tecnologias 
de Informação, 1(39), 285 - 296. Obtenido de https://www.proquest.com/scholarly-journals/diseño-de-acopio-temporal-paraclasificación-y/docview/2483100993/se-2?accountid=37408

Montecinos , E., Neira, V., Díaz, G., \& Park , J. (2019). Gobernanza democrática, descentralización y territorio: análisis del plan Chiloé en Chile. Andamios, 16(14), 413-436. doi:DOI: 10.29092/uacm.v16i41.753

Ortiz-Pech, R., Burgos-Suárez, L. C., \& Rosa., A. R.-d. (2020). Generación, reciclaje y disposición final de los principales residuos en México, 2000-2014. Gestión y Ambiente, 1, 01 -24. doi:https://doi.org/10.15446/ga.v23n1.78405

PremierI, M. E. (2020). Las estrategias de desarrollo municipal, instrumento clave para la gestión local del patrimonio cultural. Arquitectura y Urbanismo, 41(3), 67-75. doi:0258-591X

Rodríguez, M. A., \& Palomo Zurdo, R. (2020). Transparencia y economía circular: análisis y valoración de la gestión municipal de los residuos sólidos urbanos. CIRIEC-España, Revista de Economía Pública, Social y Cooperativa, 1(99), 233 -272. doi:107203/CIRIEC-E.99.16011.

Rubio-Núñez, R., Valencia, L., Peña-Cheng, L., \& Rodríguez-Muñoz, E. (2018). Importancia de la Gestión Tecnológica en los Gobiernos Municipales Mexicanos. Gestión de las Personas y Tecnología, 1-10. Obtenido de http://www.redalyc.org/articulo.oa?id=477857553008

Salazar, A. E. (2020). Indicador económico para la evaluación de la gestión municipal de los residuos valorizables en Costa Rica. Revista de Ciencias Ambientales (Trop J Environ Sci), 54, 01-015. doi:https://doi.org/10.15359/rca.54-1.1

Sánchez-Muñoz, M. D., Cruz-Cerón, J. G., \& Maldonado-Espinel, P. C. (2019). Gestión de residuos sólidos urbanos en América Latina: un análisis desde la perspectiva de la generación. Revista Finanzas y Politica Economica;(02), 317-332. doi:http://dx.doi.org/10.14718/revfinanzpolitecon.2019.11.2.6

Tahereh Malmir, Saeed Ranjbar, \& Ursula Eicker. (2020). Improving Municipal Solid Waste Management Strategies of Montréal (Canada) Using Life Cycle Assessment and Optimization of Technology Options. energies(13), 2 -15. doi:doi: 10.3390 
Vélez, A. G., Peñafiel, P. A., Heredia, M., Barreno, S. N., \& Chávez, J. F. (2019). Propuesta de sistema de gestión de residuos sólidos domésticos en la comunidad Waorani Gareno de la Amazonía Ecuatoriana. Ciencia y Tecnología, 02, 33-45. doi:10.18779/cyt.v12i2.324

Vinay Yadav, \& Subhankar Karmakar. (2021). Toma de decisiones con criterios múltiples para sistemas sostenibles de gestión de residuos sólidos urbanos. Modelado y optimización en ciencia y tecnologíasl(18). doi:https://doi.org/10.1007/978-3-030-72929-5_28

Yaashikaa , P., Kumar Ponnusamy, S., Saravanan Anbalagan, Sunita J, V., \& Racchana Ramamurthy. (2020). al. (2020). Bioconversion of municipal solid waste into biobased products: A review on valorisation and sustainable approach for circular bioeconomy. Science of The Total Environment, 778. doi:OI: 10.1016 / j.scitotenv.2020.141312

Yudith Salvador-Hernández, M. L.-F.-Z. (2018). Gestión por procesos en la participación ciudadana. Aplicación en el territorio Holguinero. Ingeniería Industrial, 40(1), 59-66. doi:https://www.redalyc.org/articulo.oa?id=360458834007 